\title{
Sequencing Lifeline Repairs After an Earthquake:
}

\section{An Economic Approach *}

\author{
Marco Casari \\ Universitat Autònoma de Barcelona \\ Departament d'Economia i d'Historia Econòmica \\ CODE, Edifici B \\ 08193 Bellaterra (Barcelona), Spain \\ fax: ++34.93 .5812461$ \\ mcasari@pareto.uab.es
}

(Corresponding author)

and

\author{
Simon J. Wilkie \\ California Institute of Technology \\ Division of the Humanities and Social Sciences, MC 228-77
}

1200 E. California Blvd.

Pasadena, CA 91125, US

fax: ++1.626 .4059841$

wilkie@bondi.caltech.edu

\begin{abstract}
${ }^{*}$ We thank Pierre Courtois, Christopher Hoag, Clara Ponsati, Keith Porter, Francesc Trillas, participants at the $58^{\text {th }}$ ES European Meeting in Stockholm, and an anonymous referee for helpful comments on earlier versions of the manuscript. The usual disclaimer applies. This work was supported by the Earthquake Engineering Research Centers Program of the National Science Foundation, under Award number EEC-9701568 through the Pacific Earthquake Engineering Research Center (PEER) and by a Marie Curie Individual Fellowship to the first author. Any opinions, findings and conclusions or recommendations expressed in this material are those of the authors and do not necessarily reflect nor those of the National Science Foundation nor those of the European Commission.
\end{abstract}




\begin{abstract}
Recoveries after recent earthquakes in the U.S. and Japan have shown that large welfare gains can be achieved by reshaping current emergency plans as incentive-compatible contracts. We apply tools from the mechanisms design literature to show ways to integrate economic incentives into the management of natural disasters and discuss issues related to the application to seismic event recovery. The focus is on restoring lifeline services such as the water, gas, transportation, and electric power networks. We put forward decisional procedures that an uninformed planner could employ to set repair priorities and help to coordinate lifeline firms in the post-earthquake reconstruction.
\end{abstract}

Keywords: utilities, inter-temporal decisions, natural disasters, mechanism design, network externalities

JEL classification: D78, D60, L97 


\section{INTRODUCTION}

Recently, many areas of public policy - from spectrum management to environmental policy - have benefited from the contributions of economists particularly the areas of game theory and mechanism design. In this study we argue that natural disaster reconstruction may greatly benefit as well from supplementing the toolbox of civil engineers with more economic reasoning. In particular, current reconstruction procedures after floods, tornadoes, earthquakes, or even limited wars could adopt decision mechanisms that are incentive compatible and that efficiently aggregate information.

The 1990s were the costliest decade on record in terms of disaster management due to seismic events, placing unprecedented pressure to improve on earthquake protection practices (Coburn and Spence 2002). Our close studies of recent post-earthquake recoveries demonstrate that the existing emergency responses present areas where their performance is not up to the task. One reason is that they have more of a combat control aspect to it, and much less of an economic assessment character. The contribution of this paper is to point to possible ways to integrate economic incentives in a traditionally command-and-control activity such as emergency plans that cope with natural disasters. We propose to apply a specific decisional mechanism, borrowed from mechanism design theory, to ex post sequence repair works, and also discuss its limitations in managing recovery after a seismic event. Instead of considering all the many aspects of natural disaster prevention and recovery (Miletti 1999; Kreimer and Arnold 2000), we focus attention because of their clear social importance - on the restoration of those essential services known in the civil engineering literature as "lifelines": water, electric power, transportation, and telephone systems.

There is a sizable literature on assessment and coverage of earthquake risks (Froot 1999; Kleffner and Doherty 1996; Penalva 2002), on preventive policies to mitigate the quake damage 
(Coburn and Spence 2002, chapters 3, 6, 8; Kunreuther and Kleffner 1992), as well as on estimating the economic cost of earthquakes (FEMA 2000). While building on these studies, we focus on the post-earthquake recovery stage and show how current practices may benefit from incorporating more explicit financial incentives for the actors involved in restoring critical lifeline services. The perspective is the one of a planner that lacks all the relevant information to implement a plan and employs economic incentives to set priorities and gather the information from others. In this respect, the present study differs from the operational research literature (Bryson et al. 2002).

Despite John Stuart Mill's comment about the resiliency of human nature, "the great rapidity with which countries recover from a state of devastation; the disappearance, in a short time, of all traces of the mischiefs done by earthquakes, floods, hurricanes, and the ravages of war" (Mill 1896), recent earthquakes in the U.S. and Japan have shown that rebuilding lifelines is a challenging task that leaves considerable room for improvement. Lack of coordination among lifeline firms, for instance, was a significant source of inefficiency (Section 2). After presenting the reconstruction problem (Section 3), we propose tools from the mechanism design literature to implement a socially optimal repair sequence (Section 4). Furthermore, a simpler, iterative procedure for the mechanism is presented (Section 5). The iterative mechanism can be safely employed when there are no network externalities, while in other cases the outcome might be sub-optimal (Section 6). Section 7 presents conclusions. 


\section{LESSONS FROM THE U.S. AND JAPANESE EARTHQUAKES}

Recent experience in the rebuilding of lifelines such as water, gas, transportation, and electric power networks after the 1994 Northridge, California, and 1995 Kobe, Japan, earthquakes ${ }^{1}$ has taught at least four important lessons (NERR 1995; US Department of Commerce 1996; Schiff 1998; Chang 2003). First, the timing of lifeline repairs has a considerable impact on social welfare. Second, decentralized decisions by lifeline firms were not socially optimal. Third, economic incentives did change the behavior of lifeline firms, and otherwise could be employed to set different priorities and substantially speed lifeline reconstruction. Fourth, at no extra cost the government could introduce a payment scheme that induces firms to incorporate into their decisions the full social costs and benefits of their repairs following a natural disaster.

Repair works after large-scale disasters take considerable time. Some individuals experience the early restoration of services, while others wait for days or even months, often at considerable cost. For example, fully restoring the Los Angeles water system to its pre-1994-earthquake conditions took more than two months and repairing the road network took six months. In the same earthquake, the major I-10 bridge in downtown Los Angeles had collapsed. For every extra day employed to rebuild the bridge, approximately 330,000 trips experienced long delays at an estimated social cost of \$1 million a day (NERR 1995, 394).

Moreover, field experience has shown clear instances where decentralized coordination among lifeline firms failed. One of the failures was the mismatch between the actions of the electric power and the gas companies:

\footnotetext{
${ }^{1}$ The Northridge (Los Angeles) earthquake occurred on January 17, 1994 at 4:31 am PST and had a moment magnitude of 6.7. The epicenter was located $32 \mathrm{~km}$ west-northwest of Los Angeles, CA, US. The Hyogoken-Nanbu (Kobe) earthquake occurred on January 17, 1995 at 5:47 am JST in an area of complex faulting located near Awaji Island and the Hanshin area of Japan and had a moment magnitude of 6.9.
} 
One of the most important lessons associated with gas system performance during the Hanshin-Awaji [Kobe] earthquake is the need to coordinate the restoration of electric power with an assessment of the state of gas system repair.

It appears that there was no pre-arranged coordination between gas and electric company personnel to restore electric service in concert with shutting off and venting gas in areas severely damaged by the earthquake... [so] that early restoration of electric power in areas with leaking gas contributed to additional fires.”(Schiff 1998).

In his post-earthquake evaluation report of the reconstruction in Japan, Schiff (1998) advocates not just inviting lifeline firms to coordinate but recommends to establish "hard, formal communication procedures $[\ldots]$ between gas, electric power, water supply, and fire department personnel" (Schiff 1998, 189-191) as integral parts of an emergency plan. Chang (2003) and Chang and Njima (2001) conducted a systemic study of transportation networks failures after the Kobe and Northridge earthquakes. With reference to the passenger railroad disruption in Kobe, they conclude that alternative repair and restoration strategies, in hindsight, would have been preferable to the actual sequence of repairs in terms of loss of transportation services.

Even in the aftermath of a natural disaster, the use of economic incentives can be as effective as the one of administrative directives, as it is demonstrated by the reconstruction of freeway bridges after the Northridge earthquake.

For Interstate 10, the contractor agreed to complete work in 140 days [for an amount of $\$ 23.8$ million], with a $\$ 200,000$ daily bonus for early completion. 
Interstate 10 was reopened on April 11, 74 days ahead of schedule, which netted the contractors $\$ 14.8$ million in bonuses. ${ }^{2}$ (NERR 1995)

As a result of this incentive scheme, the bridge was reopened in less than half of the agreed upon time, and the bonus amounted to $62 \%$ of the baseline compensation. Even so, the estimated savings to citizens from early completion of repair work was fivefold the sizable bonus paid to the contractor (NERR 1995, 392). Clearly, the lesson is that appropriately designed, incentivebased contracts can greatly affect repair works in a beneficial way for society. On the other hand, lifeline firms independently decided the pattern of repairs and the bill for Northridge earthquake was largely footed through ex-post transfers from federal and state purses. ${ }^{3}$ The approach advocated in this paper is to maintain public funding for lifeline service restoration while conditioning transfers to following an agreed sequence of repairs. The payment scheme could promote coordination among lifeline firms in such a way that induces them to incorporate into their decisions the full social costs and benefits. In the following Sections we construct a contract where a benevolent planner who does not know all the repair costs can nevertheless induce lifeline firms to implement the socially optimal repair sequence.

\footnotetext{
${ }^{2}$ The estimates of the total cost of bridge replacements in a Caltrans report on Aug 16, 1994, were the following: On route I-10, La Cienega-Venice \$4 million, La Cienega-Washington \$34.6 million, Total \$38.6 million. A similar situation was true for the I-5 freeway: "Interstate 5 repairs were more difficult than those made on I-10; nevertheless, I-5 reopened on May 17, a month ahead of schedule, resulting in bonus payments of $\$ 4.5$ million for the contractor." On route I-5, total costs were Gavin Canyon \$23.6 million, Butte Canyon \$6.8 million, total \$30.4 million (NERR 1995). As a side note, Chang and Njima (2001) conclude that highway reconstruction after the Northridge earthquake lead to lower losses in terms of transportation services than after the Kobe earthquake. ${ }^{3}$ For certain elements of the lifeline infrastructure the public purse carries the bill, while for others recovery costs are in the hands of lifeline firms. In the U.S., for any presidentially declared disaster, the related expenditures of all political jurisdictions and public utility providers qualify for a $75 \%$ federal refund, while $25 \%$ is funded by the state government. Owing to political reasons, in the case of the Northridge earthquake the federal government paid $90 \%$ and the State of California 10\% (NERR 1995. For a political economy analysis of federally declared disasters, see Garrett and Sobel (2002).
} 


\section{THE LIFELINE REPAIR PROBLEM}

The unsatisfactory performance of current seismic recovery procedures could originate from a misalignment of incentives of the various actors involved. When lifeline firms independently choose the sequence of repairs, the outcome may be different than the sequence preferred by a benevolent and fully informed planner. A sub-optimal outcome can originate either from a coordination failure among lifeline firms or from their setting repair priorities that maximize profits at the expense of society. We will now discuss the latter part.

From the standpoint of a benevolent planner, decentralized, firm decision-making may lead to a sub-optimal repair sequence because of two types of externalities: the revenue synergy and the household surplus. The former externality originates from additional revenue generated when all the different lifeline firms coordinate repair work across locations. For example, suppose an earthquake damages the water and electricity networks of two hospitals, A and B, respectively, and the water firm first repairs Hospital A, while the power firm first repairs Hospital B. The result is that in the immediate post-earthquake period, neither hospital can be opened. If instead both firms had first repaired the same hospital, one facility could be immediately operational in this critical period. The difference in firms' revenues between the coordinated but mismatched sequence is the "revenue synergy." In this example, as well as in the rest of the paper, we make an "all-or-nothing" assumption regarding benefits flowing out of a location: a location generates revenues only when all the different lifelines in that location are repaired. This assumption may be relaxed to allow positive benefits to accrue to partial restoration of key lifeline services at a location when there is a super-additivity in total benefits when all lifeline services are restored. As we shall see, whether firms coordinate can depend on how costly negotiations are.

"Household surplus," the second type of externality, provides a benefit to society greater than just increasing firms' revenues. This surplus originates both from consumer services being 
restored and the value gained by the reduction in health and public safety concerns. The analysis of an optimal repair policy must include both types of externalities because the household surplus does not need to be perfectly positively correlated with the revenue externality. For instance, consider the case where the public safety benefit is constant across households and where poorer locations have a higher household density. When consumers' income positively affects expenditures in lifeline services, each location's total household surplus may be inversely related to its revenue for firms.

Because of the relevance of the household surplus, even when firms are able to coordinate on a sequence of repair work that fully exploits the revenue externality from synergies, there is still a role for a planner. So long as critical firms are owned by the local government the conflict between public and private interests is likely to be mitigated because the firm manager is accountable to the mayor or governor. The problem is likely to be more severe when lifeline firms are privately owned.

Some notation will be introduced to better illustrate the concepts just explained. The region affected by the earthquake can be characterized as a finite collection of locations, $a_{1}, . ., a_{K}$. A location can be a physical sector, such as downtown, or a functional one, such as a set of hospitals. There are $N$ lifeline firms. For simplicity we assume that one firm is in charge of one network in all the locations (either water, gas, or electricity). Moreover, we assume that in a single period, a firm can repair only one location. The elemental decision unit is to repair network $j$ in location $k$ at time $t$.

For a single firm, a sequence $s=\left(\mathrm{a}_{1}, \mathrm{a}_{2}, \ldots, \mathrm{a}_{\mathrm{K}}\right)$ describes a way to repair the $K$ locations and $s(k)$ denotes the location that will be repaired in period $k, s \in \mathbf{s} .^{4}$ A sequence profile $S=\left(s_{1}, s_{2}, \ldots\right.$, $s_{\mathrm{N}}$ ) describes an outcome for the collection of $N$ firms, where $s_{\mathrm{j}}$ is the repair sequence for firm 
$j=1, \ldots, N$ and $\mathbf{S}$ is the feasible set, $S \in \mathbf{S}$. A repair plan $\mathrm{P}$ is an element of the feasible set $\mathbf{S}$. Moreover, the coordinated set $\mathbf{C S} \subset \mathbf{S}$ is the reduction of the strategy set, where all firms are required to choose the same sequence, $s_{\mathrm{i}}=s_{\mathrm{j}} \forall i, j \in N$. Formally $\mathbf{C S}=\{(s, s, \ldots, s)\}$ but with a slight modification in notation we write $\mathbf{C S}=s$. When some regularity conditions and the "all-ornothing" assumption are satisfied, the optimal set $S^{*}$ is a subset of the coordinated set CS.

$<$ table 1 about here $>$

$<$ table 2 about here $>$

The incentive structure embedded in current seismic recovery procedures can be described by the following "repair game" with two firms and two locations (tables 1 and 2). Consider a situation where Firm 1 prefers to repair Location 1 first (sequence $(1,2)$ ), while Firm 2 prefers to repair Location 2 first (sequence $(2,1)$ ). That is the case when in table 1 repair costs are $c_{12}=c_{11}=c_{21}=c_{22}=0$ and firms' ordinary one-period profits are $\pi_{12}=\pi_{21}=9, \pi_{11}=\pi_{22}=18$ (the first index is for the firm, the second for the location). The firms face a battle of the sexes game, where the payoff sum is 0 when there is a mismatch and 27 when the firms coordinate. In this example, while the firms are indifferent as to which sequence they coordinate, as long as they do, when household surplus in Location 1 is higher than in Location 2, i.e., $h_{1}=14$ and $h_{2}=4$ in table 2 , the planner strictly prefers sequence $(1,2)$ over $(2,1)$.

We now compare the outcomes both with and without the option to negotiate coordination by presenting three cases. In Case 1 there is no negotiation among the firms and we assume they will play the mixed strategy Nash equilibrium: Firm 1 chooses $(1,2)$ with $p=2 / 3$ and $(2,1)$ with $p=1 / 3$, while Firm 2 chooses $(1,2)$ with $p=1 / 3$ and $(2,1)$ with $p=2 / 3$. The corresponding outcome

${ }^{4}$ This paper focuses on a sequence of locations and implicitly assumes that there is an optimal sequence of repair 
is a mismatch with probability $5 / 9$ and yields an expected aggregate payoff of 12 . The difference between this equilibrium payoff and the maximum aggregate firm payoff defines the revenue externality, $27-12=15$.

\section{$<$ figure 1 about here $>$}

The interaction between firms when they have an option to negotiate repair coordination can be illustrated by figure 1 . If both firms decide to negotiate, one common repair sequence is chosen by the flip of a coin. In Case 2 negotiation costs are zero, $n c=n c_{1}+n c_{2}=0$, and both firms will choose to negotiate because that results in an improvement on their individual mixed strategy payoff, from 6 to 13.5. The planner as well prefers this to the Case 1 outcome because $36>16$ (table 2 or figure 1). While firms cannot further improve their aggregate payoffs of 27 , the planner could by always choosing sequence $(1,2)$ and earning 41 instead of randomizing between $(2,1)$ and $(1,2)$ and earning 36 . In other words, the private incentives of firms might lead to negotiate a coordinated sequence different than that desired by a benevolent planner.

In Case 3 we introduce positive negotiation costs, $n c>0$. When such costs are exceedingly high, not even a benevolent planner desires that the firms engage in negotiation, $n c>20=36-16$. The trouble with decentralized negotiation though is that it does not happen often enough. When $15>n c>20$, it is never in the firms' best interests to enter negotiation, although it would increase the planner's payoffs. Moreover, because negotiation costs need to be paid before a firm knows what the agreement will be, an asymmetric negotiation cost structure may prevent a firm from entering negotiations. For example, with $n c_{1}=0$ and $n c_{2}=8$, Firm 1 wants to coordinate as it expects a net improvement in payoffs of 7.5, but Firm 2 is not interested because $n c_{2}=8>7.5$. 
Without side transfers, no coordination takes place despite an aggregate expected net improvement for the firms of $7 .^{5}$

Actual difficulties in coordination among firms in the field suggest that negotiation costs are substantial. Sources of such costs may be the time pressure that lifeline firms face in the period immediately following a major disaster, which makes negotiation highly costly. Moreover, a firm might be bound by rights contractually granted to some customers that entitle them with a priority over others in having the service restored. As breaching these agreements could be costly, a firm might then not follow the most efficient repair plan because of the initial allocation of property rights among customers. While negotiation costs may be sizable for firms and sometimes may impede coordination on a common repair sequence, the household surpluses that are generated after a major earthquake are much larger than negotiation costs and hence coordination generates a net social benefit.

Adding high penalties for failed coordination through an emergency plan is likely to bring the chosen repair sequence closer to the planner's most preferred repair sequence. Stimulating coordination through the emergency plan sponsored by the state or the city council could also reduce negotiation costs. In fact, it provides a framework for communication and it might make implicit side transfers easier to contract upon and to enforce. Moreover, it could override without compensation the allocation of the priority rights previously contracted by lifeline firms with individual customers.

The next Section outlines an incentive-compatible decision mechanism for ex post sequencing but two remarks about the interplay between ex ante preparedness and ex post recovery should be made upfront. First, to work smoothly immediately after a seismic event, there is a need for

\footnotetext{
${ }^{5}$ When side transfers between firms are possible, in the absence of transaction costs there should be no inefficiency. An experimental study of the Coase theorem by McKelvey and Page (1997) finds support for this conclusion but also reports that inefficiencies still arise when negotiation costs are private information.
} 
establishing ex-ante an information and communication structure to allow rapid assessment and evaluation in the event of a disaster. Second, the "household surplus" should be assessed ex ante through the gathering of information about the costs of possible disruptions, especially for items of critical infrastructure (bridges, hospitals, key transmission lines, etc.). In practice, there is already a very active involvement of public-private partnerships of county and regional organizations having recovery responsibilities that could help in this task. Although not specific to the mechanism here proposed, this issue - of providing ex ante incentives to establish an infrastructure able to supply the type of information required for a given recovery management procedure - is however crucial for the success of an emergency plan. ${ }^{6}$

\section{AN INCENTIVE-COMPATIBLE DECISION MECHANISM}

An emergency plan that includes appropriate economic incentives could help to direct the repair of earthquake damage to lifeline networks along an efficient path. This Section describes a class of decision mechanisms that achieve efficiency when lifeline firms know repair costs but the planner does not. This informational asymmetry marks the difference between the decision mechanism design approach and the operational research literature. A planner with comprehensive information about the costs and benefits of all possible repair plans can compute the best plan, command each firm to execute it, and transfer appropriate funds to cover the costs. In this study we assume that in the event of an earthquake, the information acquired by firms on the repair costs $c_{\mathrm{jk}}$ is private. Without that information the planner is unable to determine the optimal plan. The decision mechanism design literature has devised ways to give firms the incentives to truthfully reveal their best estimates of repair costs and then to implement the optimal repair sequence. This approach can generate large gains for society compared to the

\footnotetext{
${ }^{6} \mathrm{We}$ thank the referee for underlying this point.
} 
current procedure of simply letting firms freely decide on repair sequences and then paying them after completion of the work. Before considering those mechanisms, we list the other assumptions about the repair problem. Some of these consider the technological environment (13), while others the behavior of the agents (4-5):

1. All-or-nothing value. At time $t$ location $k$ yields positive revenues for both firms and society only when all lifelines services have been restored, $\mathrm{I}(t, k, S)=1$. More formally, the indicator function $\mathrm{I}(t, k, S)=I\left\{\right.$ for all $j, \exists z_{j} \leq t$ such that $\left.k=s_{j}\left(z_{j}\right)\right\}$ equals 1 when location $k$ appears in the repair sequence $s_{\mathrm{j}}$ of each firm $j$ at a time $z_{j}$ earlier than or equal to time $t$, and equals 0 otherwise. The expression $s_{\mathrm{j}}(\mathrm{z})$ denotes the $\mathrm{z}^{\text {th }}$ element in the location sequence $s_{\mathrm{j}}$, where $S=\left(s_{\mathrm{j}}, s_{-\mathrm{j}}\right)$.

2. Positive household surplus. Lifeline services generate consumer surplus and reduce health and public safety concerns, $h_{\mathrm{k}} \geq 0 \forall k$.

3. Repair technology. This assumption is a list of simplifying conditions about repair technology. It makes the technical analysis of mechanisms easier.

(a) A firm needs one "period" to repair the network in one location;

(b) A firm cannot repair two locations in parallel in the same period;

(c) Firms can work simultaneously in the same location (no congestion); and

(d) Repair costs for a given lifeline do not depend on the damage level of other lifelines in the same location.

4. Firms are profit maximizers. The present value of firm $i$ 's profits has two components: a negative component that depends on the one-time repair costs $c_{\mathrm{ik}}$, and a positive component that is linked to the ordinary one-period profits $\pi_{\mathrm{ik}}$. Ordinary profits are cashed for the locations already repaired, i.e. $\mathrm{I}(t, k, S)=1$. Notice that there is a positive discounting factor of time, $\delta<1$. A firm $i=1, \ldots \mathrm{N}, \operatorname{Max}\left\{\prod_{\mathrm{i}}(S)\right\}$ over sequences $s_{\mathrm{i}} \in \mathbf{s}$. 


$$
\Pi_{\mathrm{i}}(S)=\sum_{k=1}^{K}\left(-\delta^{k-1} c_{i, s_{i}(k)}+\sum_{t=1}^{K} \delta^{t-1} I(t, k, S) \pi_{i, s_{i}(k)}\right)
$$

5. Planner's objective function. The planner's objective function includes the discounted realized household surpluses $h(S)=\sum_{k=1}^{K} \sum_{t=1}^{K} \delta^{t-1} I(t, k, S) h\left(a_{k}\right)$ as well as the sum of the firms' profits $\Pi_{i}$ (expression (1)). Notice that the discount factor is the same for firms and the planner. The planner Max $\{\mathrm{W}(S)\}$ over sequences $S \in \mathbf{S}$.

$$
\mathrm{W}(S)=h(S)+\sum_{i=1}^{N} \Pi_{i}(S)
$$

Some comments on the above assumptions are in order. We have already commented about relaxing Assumption 1 from the "all-or-nothing value" to a super-additivity condition. Assumptions 3 about the repair technology are strong and may not be a good approximation of some situations. ${ }^{7}$ Although there are desirable extensions of the framework in reference to assumptions 1 and 3, we believe the core message of the paper would not change.

Assumption 5 states that the planner is benevolent because considers firms' profits, firms' repair costs, and household surpluses. It might be argued that politicians will adopt a different objective function, particularly in cases when a decision that explicitly assigns the lowest repair priority to their location would increase the chances of alienating voters. Two remarks can be made in defense of Assumption 5. First, the additional resources generated by a more efficient repair plan may better achieve other ends. It's hard to argue for objective functions that favorably evaluate miscoordination among lifeline firms. Second, re-election goals may require giving greater weight to household surpluses instead of the profit motives of firms.

\footnotetext{
${ }^{7}$ For instance, consider "economies of contiguity" whereby fixing one length of a pipe or street makes it less costly to fix the contiguous length of pipe or street. Related issues are discussed in Section 6 (Network externalities).
} 
The decision mechanism design literature models the interaction of individuals by game theory tools, whereas institutions governing interaction are modeled as decision mechanisms. In a mechanism each individual has a message (or strategy) space, and decisions result as a function of the messages chosen (Jackson 2001). Our task is to find a mechanism for this context such that under the assumption that firms maximize profits, the outcome will be one that instead maximizes the planner's objective function.

A theme that comes out of the mechanism design literature is that it is often impossible to find decision mechanisms compatible with individual incentives that simultaneously result in efficient decisions (maximizing total welfare), the voluntary participation of the individuals, and balanced transfers (taxes and subsidies that always net out across individuals). Nevertheless, there are some important instances of where incentives and efficiency are compatible, whereas in others a "second-best" analysis is also possible (Jackson 2001). The role of transfers is to give individuals an incentive to correctly report their private information so that the collective decision made is efficient. To get a truthful revelation of the private information, adjustments need to be made so that individuals are taxed or subsidized based on the announced valuations. In some mechanisms transfers do not sum up to zero across individuals in all states.

We now present the application of a mechanism, known as the "pivotal mechanism," to earthquake repair sequencing. This application results in the choice of an efficient sequence although some individuals may not voluntarily want to participate and as a result the transfers may not be balanced. These issues will be discussed later.

Consider the $N$ lifeline firms plus a special agent representing citizens. We assume that individuals' utility is quasi-linear, i.e., it includes a numeraire commodity, generally interpreted as money, such that preferences are separable and linear in this commodity. This assumption is satisfied in the earthquake context. More specifically, firms' utility is $\mathrm{u}_{\mathrm{i}}\left(S, y_{\mathrm{i}}, \theta_{\mathrm{i}}\right)=\Pi_{\mathrm{i}}\left(S, \theta_{\mathrm{i}}\right)+y_{\mathrm{i}}$ 
for $\mathrm{i}=1, . . \mathrm{N}$, and the citizen-agent's utility is $\mathrm{u}_{\mathrm{N}+1}\left(S, y_{\mathrm{N}+1}, \theta_{\mathrm{N}+1}\right)=h\left(S, \theta_{\mathrm{N}+1}\right)+y_{\mathrm{N}+1}$. Let the choice space be $\mathrm{X}=\mathrm{SxY}$, where $\mathbf{S}$ is the set of possible repair sequences and $\mathrm{Y}=\mathbf{R}^{\mathrm{N}+1}$ are the transfers from the planner to each agent. The transfers might include an amount determined before running the mechanism in order to facilitate voluntary participation to the mechanism. An individual type $\theta_{\mathrm{i}} \in \Theta$ is determined by the profile of one-period profits or surplus and repairs cost profile, $\Theta=\mathbf{R}^{2 \mathrm{~K}}$. Repair costs for the citizen-agent are always set to zero. While the oneperiod profits and surplus are public information, the repair costs could be the private information of each firm.

As the decision mechanism designer we want to find a choice function: $F: \Theta \rightarrow X$ that, given the cost structure, picks an outcome $\mathrm{x}=\left(S^{*}, y_{1}, y_{2}, \ldots, y_{\mathrm{N}+1}\right)$, where the sequence $S^{*}$ is ex-post efficient, i.e. $\forall S \in \mathbf{S}$,

$$
h\left(S^{*}, \theta_{\mathrm{N}+1}\right)+\Sigma_{\mathrm{i}} \Pi_{\mathrm{i}}\left(S^{*}, \theta_{\mathrm{i}}\right) \geq h\left(S, \theta_{\mathrm{N}+1}\right)+\Sigma_{\mathrm{i}} \Pi_{\mathrm{i}}\left(S, \theta_{\mathrm{i}}\right)
$$

According to the pivotal mechanism, which is a special case of a Groves mechanism, the following social choice function is efficient:

$$
\begin{gathered}
y^{*}{ }_{\mathrm{i}}=\left[h\left(S, \theta_{\mathrm{N}+1}\right)+\sum_{\mathrm{j} \neq \mathrm{i}} \Pi_{\mathrm{j}}\left(S^{*}(\theta), \theta_{\mathrm{j}}\right)\right]+k_{\mathrm{i}}\left(\theta_{-\mathrm{i}}\right) \text { for } \mathrm{i}=1, \ldots \mathrm{N} \text { and } \\
y^{*_{\mathrm{i}}}=\left[\Sigma_{\mathrm{j}} \Pi_{\mathrm{j}}\left(S^{*}(\theta), \theta_{\mathrm{j}}\right)\right]+k_{\mathrm{i}}\left(\theta_{-\mathrm{i}}\right) \text { for } i=\mathrm{N}+1,
\end{gathered}
$$

where $\theta=\left(\theta_{1}, \ldots, \theta_{\mathrm{N}+1}\right)$. The function $k_{\mathrm{i}}$ is

$$
\begin{gathered}
\mathrm{k}_{\mathrm{i}}=-h\left(S_{-(\mathrm{N}+1)}\left(\theta_{-(\mathrm{N}+1)}\right), \theta_{\mathrm{N}+1}\right)-\left[\Sigma_{\mathrm{j} \neq \mathrm{i}} \Pi_{\mathrm{j}}\left(S_{-\mathrm{i}}^{*}\left(\theta_{-\mathrm{i}}\right), \theta_{\mathrm{j}}\right)\right] \text { for } \mathrm{i}=1, . . \mathrm{N} \text { and } \\
\mathrm{k}_{\mathrm{N}+1}=-\left[\Sigma_{\mathrm{j}} \Pi_{\mathrm{j}}\left(S^{*_{-(\mathrm{N}+1)}}\left(\theta_{-(\mathrm{N}+1)}\right), \theta_{\mathrm{j}}\right)\right] .
\end{gathered}
$$

The expression $S^{*}{ }_{-\mathrm{i}}\left(\theta_{-\mathrm{i}}\right)$ is the efficient sequence in the absence of agent $i{ }^{8}$ This transfer $y^{*}{ }_{\mathrm{i}}$ is always non-positive - and so the pivotal mechanism is always feasible, $\Sigma_{\mathrm{i}} y^{*_{\mathrm{i}}} \leq 0$ - and has a nice interpretation. If $i$ 's presence makes no difference in the maximizing choice, i.e., $S^{*}{ }_{-\mathrm{i}}\left(\theta_{-\mathrm{i}}\right)=$

\footnotetext{
${ }^{8}$ In particular $S_{-(\mathrm{N}+1)}\left(\theta_{-(\mathrm{N}+1)}\right)$ is the repair sequence the maximize firms' aggregate profits.
} 
$S^{*}(\theta)$, then $y^{*}=0$. Otherwise, we can think of $i$ as being "pivotal," and then $y_{\mathrm{i}}$ represents the loss in value imposed on the other individuals due to the change in decision that results from i's presence in society. The pivotal mechanism, then, has a very simple intuition behind its incentives: each individual's transfer function takes into account the marginal social impact (on other individuals) made by the individual's announcement of $\theta_{\mathrm{i}}$. When looking at this social impact, together with the individual's own selfish utility, the individual has exactly the total social value in mind when deciding on a strategy thereby leading to efficient decision-making (Jackson 2001).

The Groves mechanism presents two attractive features for our application. First it truthfully implements the efficient outcome in dominant strategies. Second, it is rather parsimonious in terms of repair cost knowledge on the side of the firms. If the equilibrium strategy is dominant, a strategy is the best regardless of the strategies chosen by other individuals. A firm does not need to condition its strategy upon what other firms will be sending as message to the planner, as it must do when the solution concept is, for instance, the Nash equilibrium. In many respects, a dominant strategy equilibrium is more robust than a Nash equilibrium one. Moreover, a firm needs to know only its own repair costs and nothing about those of other firms, and the planner can be totally uninformed.

The two drawbacks, which have already been mentioned, concern the transfers not being balanced and the voluntary participation issue. The problem of unbalanced transfers is related to the status of the special agent representing citizens and acted upon by the planner herself. When household surpluses are "responsible" for changing the sequence preferred by the firms, the citizen-agent might have to pay a transfer, $y^{*}{ }_{\mathrm{N}+1}>0$. Two cases are possible. In Case 1 , neither the planner nor the citizens are paying the transfer but yet the socially preferred sequence resulting from the mechanism is implemented. In this case, the issue is whether the planner has 
correct incentives to truthfully set the level of household surpluses $h_{k}$. If so, transfers from firms could be assigned to the citizens as well. The planner could set $h_{k}$ based on constituency interest or on bribes rather than the actual household surplus of the citizens. In Case 2, the planner does pay the transfer. In that case the pivotal mechanism becomes an instrument of discipline not only for the firms but also for the planner. The problem, then, is how to remove the transfers from the system, as the mechanism requires. One solution would be to relegate them to the upper level of government. ${ }^{9}$

The second issue is that it might not be in the lifeline firms' best interests to either voluntarily sign the contract or to carry out their contractual obligations. The emergency plan must be prepared before the event of an earthquake and hence a firm must agree to use the decision mechanism before knowing the actual repair costs. At that stage the planner may promise a transfer to firm $i$ to induce it to sign the contract. After the earthquake, the mechanism is run and the firm is legally bound to fulfill the contract although it might imply negative profits. To satisfy the constraint imposed by voluntary participation after an event, the planner might need to promise a larger transfer beforehand or else afterwards risk pressure from the firms to renegotiate the contract.

Still, if a balanced budget is considered crucial, a class of decision mechanisms exists that accomplish this and implements the efficient sequence in the Nash equilibrium strategies or one of its refinements. When preferences are quasi-linear as in this context, one can apply, for instance, the mechanism proposed by Jackson, Palfrey and Srivastava (1994). We refer to the original article for the details but will give the flavor of the mechanism. The equilibrium strategy is to truthfully report a firm's preferences in terms of all possible repair sequences and the same

\footnotetext{
${ }^{9}$ What is the size and direction of the transfers? Consider the following example without network externalities with three firms $\{A, B, C\}$ and two locations. Valuations of locations $(1,2)$ are $\{(10,30),(20,30),(30,10)\}$ for the firms and $(35,10)$ for the households. The sequence that maximizes aggregate profits is $(2,1)$ while the planner prefers $(1,2)$,
} 
information about another firm. The optimal sequence is implemented when, for all firms $i=1, . ., \mathrm{N}$, firm $i$ 's announcement about firm $i+1$ coincides with firm $i+1$ 's announcement about itself. Otherwise, an outcome undesired by the firms is implemented.

This other mechanism also has drawbacks. The major one is that it works when a firm knows not only its own costs but also the cost structure of at least one other firm. Hence, the pivotal mechanism is less demanding in this respect. Although several mechanisms could be compared, the conclusion is that tools exist to assist the planner in choosing the most efficient repair sequence.

\section{AN ITERATIVE DECISION RULE}

A drawback of the decision mechanisms described in the previous Section is the considerable information about repair costs that firms are assumed to know and to report to the planner. This Section illustrates possible directions for weakening these requirements.

Because of the high dimensionality of the strategy space for location sequencing, firms are required to submit a large number of cost estimates in order to implement the contract described above. As the mechanism stands, a firm $i$ has to submit for each of the possible $K$ ! sequences $s \in \mathbf{S}$ a cost vector $c_{\mathrm{i}}(s)=\left(c_{\mathrm{i}, s(1)}, c_{\mathrm{i}, s(2)}, . ., \quad c_{\mathrm{i}, s(K)}\right)$, where $c_{\mathrm{i}, s(k)}$ denotes the cost to repair location $s(k)$ given that locations $s(1), s(2), . ., s(k-1)$ have already been repaired. The number of cost estimates that describe the full cost structure of a firm is $r=\sum_{j=1}^{K} \frac{K !}{(K-j) !}$. To give an idea of the magnitude, if the region is divided into $K=10$ locations, $r=9,828,000$. Although most of the cost estimates reported will likely be repetitions of identical numbers, the amount of reporting required by the mechanism remains remarkably high. A dramatic reduction of the message space

which maximize social surplus. As households make the outcome change, they are taxed for 10 (70-60). Moreover 
can be achieved without compromising the achievement of the optimal repair sequence when the following technological condition is satisfied in addition to the list in Section 4:

3(e) The cost of repairing the damage in a location $a_{k}$ does not depend on the damage level of the same network in other locations $\mathrm{a}_{1} l \neq k$.

When Assumption 3 (e) is met, a simpler, iterative version of the mechanism can be run. Instead of determining the whole sequence of locations in period zero, the iterative mechanism chooses just the next location to be repaired. After all lifelines are restored in one location, firms would again be asked to report repair costs on all the remaining locations, until all $K$ have been repaired. In this simpler mechanism a firm $i$ at period $t$ submits its cost estimates $c_{\mathrm{i}}$, si $(t)$ given a common history of locations that have already been repaired, $s(1), s(2), . ., s(t-1)$. When all $K$ periods are considered, the number of cost estimates to be reported relative to the cost structure of a firm is $r=(K+1) K / 2$, considerably less than before (for $K=10, r=55$ ).

Besides reducing the strategy space, the iterative version of the mechanism has the advantage of allowing to incorporate into the decision-making process additional information on repair costs that might become available during the repair works. A similar updating is already used by lifeline firms for ordinary maintenance work, where the information acquired helps to schedule following maintenance work. Committing to a repair sequence in period zero could result in a sub-optimal choice if new information is acquired during the repair process.

\section{NETWORK EXTERNALITIES}

While the full-scale mechanism outlined in Section 4 always implements the optimal repair sequence, the iterative mechanism from the previous Section may not lead to the optimal sequence when there are network externalities. There is a network externality when the cost of 
repairing the damage in a location depends on the damage level of the same network in other locations. The impact of network externalities on the outcome of the iterative mechanism is now discussed.

$$
\begin{aligned}
& <\text { figure } 3 \text { about here }> \\
& <\text { table } 3 \text { about here }>
\end{aligned}
$$

Consider the scenario illustrated in figure 3 where the water network consists of two aqueducts A and B (assume that other lifelines were not damaged). While Aqueduct B serves only Location 3, Aqueduct A serves Locations 1 and 2. In order to provide water to Location 1, the aqueduct must be repaired all the way upstream, i.e. also in Location 2. Hence, the current cost of restoring water supply in Location 1 varies whether Location 2 has already been repaired or not in previous periods. That is an instance of network externalities. We now compare the optimal repair sequence, $S^{*} \in \mathbf{S}$, with the repair outcome that results from the decentralized interaction of lifeline firms, $D S \in \mathbf{S}$, and with the outcome when employing the iterative mechanism described in the previous Section, $M S \in \mathbf{S}$. In this example the adoption of the iterative mechanism leads to an outcome that is worse than having no mechanism at all. ${ }^{10}$

The iterative mechanism falls into a trap because it does not anticipate the consequences of today's repair decision on future repair costs. In fact, the repair cost reported by a firm has two distinct components, $c_{\mathrm{ik}}=d_{\mathrm{ik}}+e_{\mathrm{ik}}$, the cost to repair lifeline $i$ within location $k, d_{\mathrm{ik}}$, and the cost for those lifeline $i$ repairs outside location $k$, $e_{\mathrm{ik}}$, that are nonetheless needed in order to provide service within location $k .{ }^{11}$ Whenever $c_{\mathrm{ik}}$ depends on past history of repairs, there is a network externality and Assumption 3(e) does not hold.

\footnotetext{
${ }^{10}$ The example is biased on purpose against the mechanism, as it ignores coordination issues among firms - but is useful to make a point.

${ }^{11}$ There is a third component, $g_{i k}$, which is the cost to repair the minor branches of the networks within location $k$. Without loss of generality we assume that $\mathrm{g}_{\mathrm{ik}}=0$. In the example, we also assume that $\mathrm{e}_{\mathrm{i} 1}=\mathrm{d}_{\mathrm{i} 2}$.
} 
Among the six possible repair sequences described in table 3, the planner's optimal sequence is $S^{*}=(1,2,3)$. This outcome maximizes the sequence of net benefits, $(-1,13,17)$, which is the difference between the profile of benefits for all the locations that have already been repaired $\left(\pi_{1}+h_{1}, \pi_{1}+h_{1}+\pi_{2}+h_{2}, \pi_{1}+h_{1}+\pi_{2}+h_{2}+\pi_{3}+h_{3}\right)=(7,13,18)$ and the profile of costs $\left(d_{1}+d_{2}, 0, d_{3}\right)=(8$, $0,1) \cdot{ }^{12}$

Instead, the iterative mechanism yields a sequence $M S=(3,2,1)$, which is not optimal. In the first period, when the reported cost vector $\left(c_{1}, c_{2}, c_{3}\right)=(8,5,1)$ is compared with the three-period benefits of each alternative $\left(3\left(\pi_{1+} h_{1}\right), 3\left(\pi_{2}+h_{2}\right), 3\left(\pi_{3}+h_{3}\right)\right)=(21,18,15)$, Location 3 is chosen because it yields the highest net benefit (i.e. 15-1). In the second period, with reported costs of $(8,5, \cdot)$ and benefits of $\left(2\left(\pi_{1+} h_{1}\right), 2\left(\pi_{2+} h_{2}\right), \cdot\right)=(14,12, \cdot)$, Location 2 is chosen (net benefit 12-5). The resulting net benefit profile $(4,6,15)=(5,11,18)-(1,5,3)$ has a lower net present value than the profile for $S^{*}$.

Finally, a firm would have chosen $D S=(2,1,3)$ to get the highest net profit profile $(0,6,11)$. Although not optimal for the planner, the net benefit profile for $D S,(6,13,18)-(5,3,1)=(1,10$, 17) has a higher net present value than for the sequence $M S$ generated by the iterative mechanism. $^{13}$

A partial solution to network externalities is redistricting. So far we have been agnostic about the process of partitioning the region into locations, but such a task is an integral part of writing an emergency plan. The choice about the number of locations and their borders is not a trivial one and may influence the efficiency of the iterative mechanism outcome. In the above example, a consolidation of Locations 1 and 2 into a macro-location would eliminate network externalities.

\footnotetext{
${ }^{12}$ The sequence is optimal for discount factor $\delta>0.67$. Repair costs are $c_{1}=8, c_{2}=0$ for sequence $(1,2,3)$ and $\mathrm{c}_{1}=3$, $\mathrm{c}_{2}=5$ for sequence $(3,2,1)$.

${ }^{13}(2,1,3)$ maximizes net profits for $\delta>0.5$ and yields higher net benefits than $(3,2,1)$ for $\delta>0.59$.
} 
Once the iterative mechanism has selected a macro-location sequence, a lower-level mechanism could select micro-location sequences within each macro-location.

Still, restructuring the region into macro-locations is not completely satisfactory for three reasons. First, the planner must know how to properly redistrict the region into a location, which is a rather technical task. ${ }^{14}$ Second, the larger the macro-location the smaller the potential surplus gains from applying the mechanism. Consider that a macro-location for a single lifeline such as electricity can be as large as — or larger than — the whole region under analysis. As an effect of the Northridge earthquake in Los Angeles, for example, 150,000 customers in rural Idaho lost power for three hours, as did power customers as far as Washington, Montana, and British Columbia (NERR 1995, 189). Third, when more than one lifeline network overlaps on the same map it may be impossible to divide the region in a way to eliminate all network externalities. To sum up, redrawing locations can solve the problem of network externalities in special cases but not in general, and hence the iterative mechanism can lead to sub-optimal outcomes.

\section{CONCLUSIONS}

While coping with natural disasters has long been regarded as essentially an engineering task (Bryson et al. 2002; Hirshleifer 1991), we argue that the introduction of economic techniques for the aggregation of information and the alignment of incentives in emergency plans for disasters can substantially improve social welfare.

Our focus is on post-earthquake reconstruction and, in particular, restoring essential, or "lifeline" services such as water, power, transportation, and telephone services. A close consideration of the experiences of rebuilding lifeline networks after the 1990s earthquakes in the U.S. and Japan has made it apparent that current emergency plans are missing out on

\footnotetext{
${ }^{14}$ In this work, the social planner is assumed not to be ignorant about the cost structure of firms.
} 
potentially large welfare gains by not having the proper decision mechanisms in place (NERR 1995; Schiff 1998; U.S. Department of Commerce 1996; Chang 2003). Sources of inefficiencies lie in the dispersion of information about the costs and benefits of alternative reconstruction plans among various key participants and in a misalignment of economic incentives between the lifeline repair firms and society. We show how mechanism design theory can assist policy makers in acquiring the information to identify the best repair plan and in writing incentivecompatible contracts to implement that plan. The proposed approach can also be applied more generally to the recovery after other major natural disasters such as floods, tornadoes, and even to limited wars.

While governments have covered a large portion of repair costs after earthquakes, they have permitted lifeline firms to decide what locations to repair and when to do it. Such decentralized decision-making is likely to generate inefficient outcomes because of coordination failures among lifeline firms and because of wrong repair priorities. Coordination failures may arise when there is a mismatch in post-earthquake repair sequences among lifeline firms. For example, if the gas firm repairs the west side of town while the power firm restores electricity in the east side of town, all buildings are unusable because the west side lacks electricity and the east side has a fire hazard generated by gas leaks. Although in principle side transfers among firms should be enough to generate coordination, reconstruction reports indicate that coordination did not always occur (NERR 1995; Schiff 1998). Furthermore, wrong repair priorities can be set by firms when their profits are not strongly correlated with the consumer surplus resulting from services being restored and with the value gained by the reduction in health and public safety concerns. By contrast, a benevolent planner in such situations would choose a repair plan that maximizes social welfare. 
We show that an emergency plan could avoid both coordination failures and the setting of wrong priorities by including a properly designed contract with lifeline firms. This type of contract has been studied in the decision mechanism design literature (Jackson 2001; Jackson, Palfrey, and Srivastava 1994). In general, firms are asked to reveal their private information about repair costs, and a decision about a sequence of locations to be repaired is generated by aggregating all the information. Transfers could be done from or to the firms. The role of transfers is to give firms an incentive to report correctly their private information. We present a class of mechanisms that achieves this goal and we apply it in the context of the pivotal mechanism, a classic example of incentive-compatible mechanism where truth telling is the equilibrium strategy for the firms. The pivotal mechanism, however, does not ensure that the "budget always balances." That is, the sum of the payments by firms does not necessarily equal the sum of claims for payment by stakeholders. This, we believe, leads to a natural role for the federal government or, as a last resort, another disaster relief provider such as FEMA.

While current emergency plans would greatly benefit from incorporating the principles of a mechanism design, more work is needed to extend the outlined framework and to study it empirically. Some stark assumptions about repair technology and flow of benefits from newly repaired locations are in need of relaxation if the mechanism is going to be applied to a field situation. Moreover, it must be conceded that firms are required to report to the planner a remarkably high amount of information. In response to this criticism, we have put forward an iterative version of the full-scale mechanism whereby firms are able to report repair cost estimates for a considerably lower number of alternative scenarios. Unfortunately, this simpler mechanism guarantees an optimal outcome only under restrictive conditions placed on the cost structure. Future research should explore trade-offs between the reduction in the amount of information to be reported and loss in terms of a second-best outcome. Before its adoption, an 
empirical validation of a decision mechanism is advisable. One could carry out either an experimental study or a computational simulation of a post seismic scenario or both.

Lifeline service restoration is an aspect of disaster relief management that deserves more attention because there has been a non-trivial level of mismanagement despite stakes being considerably high. Setting up a framework among lifeline firms with explicit financial incentives of the type suggested in this paper would be a step toward a more efficient post-disaster recovery. 


\section{REFERENCES}

Bryson, K.-M., H. Millar, and A. Joseph. 2002. "Using formal MS/OR modeling to support disaster recovery planning," European Journal of Operational Research, 141(3):679-688.

Chang, S. E. 2003. "Transportation Planning for Disasters: An Accessibility Approach," Environment and Planning, A, 35(6):1051-1072

Chang, S. E. and N. Njima. 2001. "Measuring Post-disaster Transportation System Performance:

The 1995 Kobe Earthquake in Comparative Perspective," Transportation Research, A, $35(6): 475-494$

Coburn, A. and R. Spence. 2002. Earthquake Protection, 2nd Edition, Wiley

FEMA, Federal Emergency Management Agency 2000. ”HAZUS99 Estimated Annualized Earthquake Losses for the United States," FEMA Working Paper 366 (September).

Froot, K. (Ed). 1999. The Financing of Catastrophe Risk, Chicago, IL, University of Chicago Press

Garrett, T. A. and R. S. Sobel. 2002. "The political economy of FEMA disaster payments," Federal Reserve Bank of St. Louis, Working Paper 2002-012B.

Hirshleifer, J. 1991. “Disaster and Recovery,” Department of Economics, University of California, Los Angeles, Working Paper No. 639.

Jackson, M.O. 2001. “Mechanism Theory," In The Encyclopedia of Life Support Systems, edited by EOLSS, Forthcoming

Jackson, M.O., Thomas Palfrey, and Sanjay Srivastava 1994. "Undominated Nash Implementation in Bounded Mechanisms," Games and Economic Behavior, 6:474-501. 
Kleffner, A.E. and N.A. Doherty. 1996. "Costly Risk Bearing and the Supply of Catastrophic Insurance," Journal of Risk and Insurance, 63(4):657-671.

Kreimer, A. and M. Arnold. (Eds). 2000. "Managing Disaster Risk in Emerging Economies," World Bank Disaster Risk Management Series, no. 2. Washington, D.C..

Kunreuther, H. and A.E. Kleffner. 1992. "Should Earthquake Mitigation Measures be Voluntary or Required?," Journal of Regulatory Economics, 4(4):321-333.

McKelvey, R. and T. Page. 1997. "An Experimental Study of the Effect of Private Information in the Coase Theorem," Social Science Working Paper 1018, Pasadena, Caltech.

Miletti, D. (Ed). 1999. Disasters by Design: A Reassessment of Natural Hazards in the United States, Washington, DC: Joseph Henry Press.

Mill, J. S. 1896. Principles of Political Economy, New York, Appleton \& Co.

NERR (Northridge Earthquake Reconnaissance Report). 1995. Earthquake Spectra, Supplement, Vol.11 (April).

Penalva, J. 2002. "Insuring California Earthquakes and the Role for Catastrophe Bonds," Journal of Risk Finance, 3(4):54-72.

Schiff, A.J. (Ed). 1998. "Hyogoken-Nanbu Kobe. earthquake of January 17, 1995, Lifeline performance," American Society of Civil Engineers, Technical Council on Lifeline Earthquake Engineering, Monograph No. 14 (September).

United States Department of Commerce. 1996. “The January 17, 1995 Hyogoken-Nanbu Kobe. Earthquake, Performance of structures, lifelines, and fire protection systems," Gaithersburg, Technology Administration, National Institute of Standards and Technology Special Publication 901, ICSSC. 
Table 1: Firms' Repair Game

\begin{tabular}{|c|c|c|c|}
\hline \multicolumn{2}{|c|}{} & \multicolumn{2}{|c|}{ Firm 2 } \\
\cline { 3 - 4 } \multicolumn{2}{|c|}{} & $(1,2)$ & $(2,1)$ \\
\hline \multirow{3}{*}{ Firm 1 } & $(1,2)$ & $\pi_{11}-c_{11}-\delta c_{12}$ & $-\left(c_{11}+\delta c_{12}\right)$ \\
& & $\pi_{21}-c_{21}-\delta c_{22}$ & $-\left(c_{22}+\delta c_{21}\right)$ \\
\cline { 2 - 4 } & $(2,1)$ & $-\left(c_{12}+\delta c_{11}\right)$ & $\pi_{12}-c_{12}-\delta c_{11}$ \\
& & $-\left(c_{21}+\delta c_{22}\right)$ & $\pi_{22}-c_{22}-\delta c_{21}$ \\
\hline
\end{tabular}

Notes: One-period profits, $\pi_{12}, \pi_{11}, \pi_{21}, \pi_{22}$ (first index is for firm, second index for the location).

Repair costs, $\mathrm{c}_{12}, \mathrm{c}_{11}, \mathrm{c}_{21}, \mathrm{c}_{22}$; discount factor $\delta$; to obtain the gross payoffs, add $\delta\left(\pi_{12}+\pi_{11}\right)$ to payoffs of Firm 1 and $\delta\left(\pi_{22}+\pi_{21}\right)$ to payoffs of Firm 2 .

Table 2: Planner's Repair Payoffs

\begin{tabular}{|c|l|l|l|}
\hline \multicolumn{2}{|c|}{} & \multicolumn{2}{|c|}{ Firm 2 } \\
\cline { 2 - 4 } \multicolumn{2}{|c|}{} & $(1,2)$ & $(2,1)$ \\
\hline \multirow{3}{*}{ Firm 1 } & $(1,2)$ & $\pi_{11}-\mathrm{c}_{11}-\delta \mathrm{c}_{12}+\pi_{21^{-}-\mathrm{c}_{21^{-}}}$ & $-\left(\mathrm{c}_{11}+\delta \mathrm{c}_{12}\right)-$ \\
& & $\delta \mathrm{c}_{22}+\mathbf{h}_{1}$ & $\left(\mathrm{c}_{22}+\delta \mathrm{c}_{21}\right)$ \\
\cline { 2 - 4 } & $(2,1)$ & $-\left(\mathrm{c}_{12}+\delta \mathrm{c}_{11}\right)-$ & $\pi_{12}-\mathrm{c}_{12}-\delta \mathrm{c}_{11}+\pi_{22^{-}-\mathrm{c}_{22^{-}}}$ \\
& & $\left(\mathrm{c}_{21}+\delta \mathrm{c}_{22}\right)$ & $\delta \mathrm{c}_{21}+\mathbf{h}_{2}$ \\
\hline
\end{tabular}

Notes: The planner's payoff is the sum of Firm 1 and Firm 2 payoffs plus household surpluses.

$\mathrm{h}_{\mathrm{k}}=$ household surplus from location $k$; to obtain the gross payoffs, add $\delta\left(\mathrm{h}_{1}+\mathrm{h}_{2}+\pi_{12}+\pi_{11} \pi_{22}+\pi_{21}\right)$; Feasible Set $\mathbf{S}$ : $\{((1,2),(1,2)),((1,2),(2,1)),((2,1),(1,2)),((2,1),(2,1))\}$; Coordinated Set CS: $\{((1,2),(1,2)),((2,1),(2,1))\}$.

Table 3: A scenario with network externalities

\begin{tabular}{|c|c|c|c|c|}
\hline $\begin{array}{c}\text { Location } \\
k\end{array}$ & $\begin{array}{c}\text { Repair cost } \\
\text { within location } k \\
d_{k}\end{array}$ & $\begin{array}{c}\text { Repair cost } \\
\text { outside location } k\end{array}$ & $\begin{array}{c}\text { Firm's ordinary } \\
\text { one-period profits }\end{array}$ & $\begin{array}{c}\text { Household } \\
\text { surplus } \\
e_{k}\end{array}$ \\
\hline 1 & 3 & $\mathrm{~d}_{2}=5$ & 4 & $h_{k}$ \\
2 & 5 & 0 & 5 & 1 \\
3 & 1 & 0 & 3 & 2 \\
\hline
\end{tabular}




\section{Figure 1: Firms' repair game with the option to negotiate coordination}

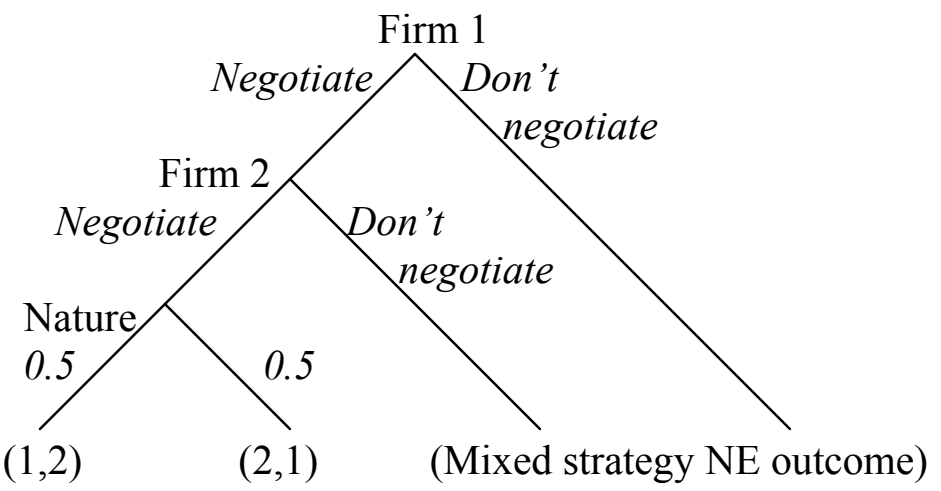
$18-\mathrm{nc}_{1}$
$9-\mathrm{nc}_{1}$
6
6
Firm 1's payoff
$9-\mathrm{nc}_{2}$
$18-\mathrm{nc}_{2}$
6
6
Firm 2's payoff
$41-\mathrm{nc}_{1}-\mathrm{nc}_{2}$
$31-\mathrm{nc}_{1}-\mathrm{nc}_{2}$
16
16
Social planner's payoff

Note: Without negotiation, the game is defined by table 1 when $\mathrm{c}_{12}=\mathrm{c}_{11}=\mathrm{c}_{21}=\mathrm{c}_{22}=0, \pi_{12}=\pi_{21}=9$, $\pi_{11}=\pi_{22}=18, \mathrm{~h}_{1}=14$, and $\mathrm{h}_{2}=4$. The mixed strategy Nash equilibrium outcome is a mismatch with $\mathrm{p}=5 / 9$, sequence $(2,1)$ with $\mathrm{p}=2 / 9$ and sequence $(1,2)$ with $\mathrm{p}=2 / 9$.

Figure 2: A scenario with network externalities

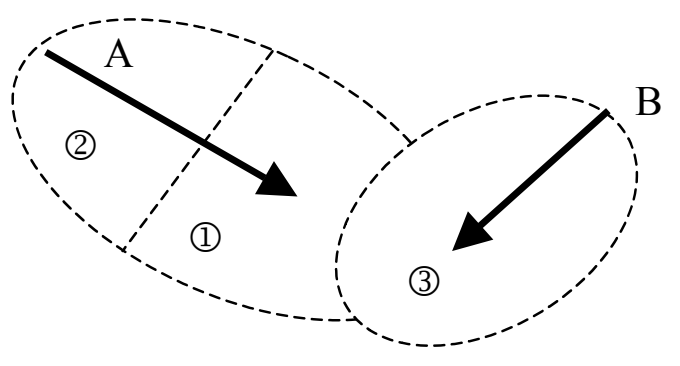

